\title{
O que os usuários pensam efalam do Sistema Ú nico de Saúde? Uma análise dos significados à luz da carta dos direitos dos usuários
}

\author{
What do the users think and say about the Brazilian Health System \\ (SUS)? An analysis of meanings based on the users' rights booklet
}

\author{
Dirce Stein Backes ${ }^{1}$ \\ M agda Santos Koerich ${ }^{2}$ \\ Anna Carolina Ribeiro Lopes Rodrigues ${ }^{3}$ \\ Livia Crespo Drago ${ }^{3}$ \\ Patrícia Klock ${ }^{4}$ \\ Alacoque Lorenzini Erdmann ${ }^{5}$
}

${ }^{1}$ Departamento de Enfermagem, Centro

Universitário Franciscano. Rua Duque de Caxias 938. 97010-200 Santa M aria RS. backesdirce@ig.com.br ${ }^{2}$ Departamento de Patologia, Universidade Federal de Santa Catarina. ${ }^{3}$ Curso de Graduação em Enfermagem, Universidade Federal deSanta Catarina.

${ }^{4}$ Hospital Universitário, UniversidadeFederal de Santa Catarina. ${ }^{5}$ Departamento de Enfermagem, U niversidade Federal deSanta Catarina.
Abstract This study is the result of an expanded research-action project aimed at presenting and discussing the main thematic units that emerged from discussions conducted with a group of users about booklet regarding users' rights from the SUS (Brazilian Health System). Between M ay and July 2007, weekly meetings wereheld, recorded and followed by qualitative research data analysis until reaching the thematic units. The results show that granting access to the public health system is not enough. We must create political awareness so that users do not become mere recipients or interlocutors of government proposals. We must ensure that all social actors engage themselves in the fight for the transformation of society by making use of their rights and fulfilling their duty.

Key words Nursing, Brazilian Health System, Patient rights, Research in nursing
Resumo 0 presente estudo é fruto de um projeto ampliado depesquisa-ação quetem por objetivo apresentar ediscutir as opiniões, percepções $/$ ou experiências deum grupo deusuários do SU S sobrea cartilha dos di reitos dos usuários. Os encontros foram realizados semanalmente e, posteriormente, a coleta se guiu-se com os procedimentos de análise dos dados das pesqui sas qualitativas, até alcançar as unidades temáticas. Os resultados demonstram que não basta garantir o acesso ao sistema público de saúde. É preciso criar uma consciência política para que os usuários não se tornem meros receptores ou interlocutores das propostas governamentais. É preciso que todos os atores sociais estejam engajados e comprometidos, por meio de seus direitos e deveres, na luta pela transformação da sociedade.

Palavras-chave Enfermagem, Sistema Único deSaúde, Direitos do paciente, Pesquisa em enfermagem 
Introdução

Todo cidadão brasileiro tem direito de acesso ao Sistema Único de Saúde (SUS), conforme a Lei 8.080, de 1990. A utilização dos serviços prestados pelo SUS, por sua vez, deverá ser garantida através de políticas e ações de promoção, proteção e recuperação da saúde que possi bilitem, também, a participação popular nas decisões e na implementação das ações.

M as, o que os usuários entendem por SUS? Tal questão é fundamental para compreender 0 que significa ter acesso, direitos, deveres e responsabilidades para com as políticas públicas.

O SUS é um sistema de saúde regionalizado e hierarquizado que integra o conjunto das ações de saúdeda União, estados, Distrito Federal emunicípios, no qual cada parte cumpre funções e competências específicas, porém articuladas entre si, 0 que caracteriza os níveis de gestão do SUS nas três esferas governamentais ${ }^{1}$.

O SUS, sob esse enfoque, deveser reconhecido, apesar da descrença de muitos, como um importante mecanismo de cobertura social no que diz respeito à saúde, servindo como um apoio para superar a fragmentação e a exclusão crescentes na sociedade brasileira atual. Convém sinalizar, no entanto, quetanto os gestores, profissionais eusuários, quanto o governo são responsáveis pela coordenação de esforços para estruturar um SU S eficiente e eficaz. Logo, quanto mais o planejamento desse sistema estiver articulado e integrado com a coletividade, tanto maior será a garantia de um serviço de saúde com qualidade e eqüidade.

É inegável que o SUS, com o passar dos anos, tenha conseguido uma ampliação significativa em termos de cobertura e acesso. Dentre as conquistas no âmbito governamental, que já são referência no país, destaca-se a articulação do M inistério Público com entidades civis na defesa do caráter público do SUS, possibilitando um sistema não mais de caráter emergencial, mas a garantia da continuidade através da integração de diversas políticas públicas. Nessa direção, o SUS favorece uma integração não apenas das políticas, mas também da população benefíciária a fim de estimular parcerias, fomentar o espírito solidário e gerar resultados mais efetivos do ponto de vista do impacto social do que aqueles obtidos com programas fragmentados ${ }^{2}$.

N esse processo, tornam-se evidentes várias iniciativas de articulação interinstitucionais que congregam o SUS, expressas através de entidades governamentais, não-governamentais, privadas e de ensino, as quais atuam junto aos municípios para o acompanhamento da execução das políticas públicas locais em cada uma das respectivas áreas temáticas. Podem ser destacadas: Grupo de TrabaIho Amazônico (GTA), composto por mais de seiscentas ONGs da Amazônia, que vêm fortalecendo a participação da sociedade civil na formulação de propostas, projetos e políticas públicas para o desenvolvimento sustentável da região; Fórum Brasileiro de Organizações Não-Governamentais e M ovimentos Sociais para o Desenvolvimento Sustentável e M eio Ambiente (FBOM S); Articulação Nacional de Experiências e Práticas de Educação Popular em Saúde (ANEPS), com a missão de fortalecer as práticas de educação popular em todo 0 país; Atenção Primária Ambiental (APRIM A), grupo de trabalho formado pela Coordenação N acional de Vigilância Ambiental do M inistério da Saúde, para implementação da atenção primária ambiental como estratégia intersetorial de atenção primária à saúde; Pólo de Educação Permanente para Profissionais do SUS (PEP), entre outros ${ }^{1}$.

Esseúltimo grupo, particularmente, merecedestaque pelo compromisso com a mudança, no sentido de suprimir a noção programática fragmentária e promover a instituição de mecanismos de valorização do potencial humano de mobilização ede desestabilização das estruturas tradicionais. N esse sentido, os Pólos deEducação Permanente em Saúde, como novas estruturas organizativas, contribuem para o avanço do SUS através da superação dos reducionismos da formação e das práticas clínicas para a promoção da educação permanente das equipes de saúde, a capacidade resolutiva dos serviçose, principalmente, para aqualificação à atenção integral à saúde e ampliação da gestão social sobre as políticas públicas.

Além dos programas quejá mencionamos, ainda podem ser citados aqueles voltados para a humanização em saúde no sentido de resgatar valores como a solidariedade e a ética da responsabilidade. Um deles éo Programa Nacional de Humanização dos Serviços de Saúde, que, dentre outros objetivos, visa à melhoria na qualidade da assistência e a redução dos custos com as longas permanências ${ }^{3}$. Associado a este, foi elaborada a Cartilha dos Direitos dos U suários da Saúde, regida por seis princípios básicos de cidadania, que asseguram a qualquer cidadão o direito ao ingresso digno no sistema de saúde, seja ele público ou privado 4 .

Apesar das experiências que já são referência no Brasil, ainda resta muito por ser feito. É evidente, de acordo com Soares², que o caráter público da fiscalização por parte de órgãos do próprio Estado ainda tem muito a avançar, e esse avanço não se dá de maneira uniforme em todo o território 
nacional, mas éum espaço potencial que necessita e deve ser fortalecido na construção de um Estado verdadeiramente democrático. A luta política eideológica não pode ficar apenas no terreno do "ser contra o governo". É preciso, portanto, superar a marca histórica do conservadorismo da nossa sociedade, bem como a hegemonia do modelo biomédico que ainda prevalece no âmbito das idéias como fruto de uma visão reducionista.

$\mathrm{N}$ ão basta, em outras palavras, garantir o acesso e/ou o direito ao sistema público desaúde. M uito além de possibilitar o acesso, é preciso criar uma consciência política nos usuários para que não se tornem meros receptores ou interlocutores das propostas governamentais. É preciso que todos os atores sociais estejam engajados e comprometidos, por meio de seus direitos e deveres, na luta pela transformação da sociedade. Com base nesses pressupostos, objetiva-se, com este estudo, apresentar ediscutir, à luz do pensamento comple$\mathrm{xo}$, as principais unidades temáticas que emergiram a partir de encontros de discussão realizados com usuários do SUS sobre a Carta dos Direitos dos U suários da Saúde.

\section{M etodologia}

0 presente estudo é fruto de um projeto ampliado de pesquisa-ação, em fase de execução, que tem como objetivo geral analisar e discutir a Carta dos Direitos dos U suários da Saúde, recentemente divulgada pelo M inistério da Saúde, com os usuários de um hospital público da Grande Florianópolis.

A pesquisa-ação pode ser caracterizada como um tipo de pesquisa social com base empírica, concebi da e real izada em estreita associação com uma ação ou com a resolução de um problema coletivo no qual os pesquisadores e os participantes, representativos da situação e/ou do problema, estão envolvidos de forma cooperativa e participativa $a^{5-7}$.

N essa perspectiva, a pesquisa-ação tende a se impor, gradativamente, como um importante mé todo de pesquisa na saúde em outros setores sociais, com a finalidade de provocar transformações por meio da pesquisa e da ação, simultaneamente. N essa direção, as pesquisadoras intentaram instrumentalizar os atores do SUS para se tornarem capazes de responder com mais consciência aos problemas da situação em que vivem, em particular sob a forma de estratégias de ação transformadora e, ainda, facilitar a busca de soluções face aos problemas para os quais os procedimentos convencionais têm contribuído pouco.
0 processo de pesquisa-ação foi iniciado no mês de maio de 2007, com um grupo de dez usuárias do SUS, mães de crianças internadas na Unidade de Terapia Intensiva Neonatal, por meio de encontros semanais, com cerca de uma hora de duração cada, sobre os problemas observados nas unidades de saúde onde eram atendidas, além da discussão sobre os princípios que compõem a Carta, sempre buscando soluções e propostas de participação conjunta. Participaram do grupo de discussão duas doutorandas, duas estudantes de graduação em Enfermagem e uma Enfermeira da Unidade de Terapia Intensiva Neonatal.

As pesquisadoras levaram para a discussão, inicialmente, a Carta dos Direitos dos Usuários da Saúde, que apresenta os seguintes princípios: (1) todo cidadão tem direito ao acesso ordenado e organizado aos sistemas de saúde; (2) todo cidadão tem direito a tratamento adequado e efetivo para seu problema; (3) todo cidadão tem direito ao atendimento humanizado, acolhedor e livre de qualquer discriminação; (4) todo cidadão tem direito a atendimento que respeite a sua pessoa, seus valores e seus direitos; (5) todo cidadão também tem responsabilidades para que seu tratamento aconteça da forma adequada; (6) todo cidadão tem direito ao comprometimento dos gestores da saúde para que os princípios anteriores sejam cumpridos 4 .

A apresentação e discussão da temática constituíram-se, ao longo dos seis primeiros encontros, em momentos de desabafo e crítica em relação à assistência recebida, principalmente nas Unidades Básicas de Saúde. Desse modo, considerando a pertinência e similaridade dos problemas levantados, optou-se por elaborar esse artigo, mesmo não tendo concluído a pesquisa, a fim de ampliar as discussões para o mundo acadêmico e a sociedade em geral.

Os aspectos éticos da pesquisa são expressos por meio do cumprimento das recomendações da Resolução no 196/96, do Conselho Nacional de Saúde, que prescreve a ética na pesquisa com seres humanos. Foi solicitada a autorização à direção da instituição para o desenvolvimento das atividades, assim como ao Comitê de Ética em Pesquisa com Seres Humanos (CEP) da Universidade Federal de Santa Catarina (UFSC), recebendo aprovação sob o número 074/2007. Aos sujeitos da pesquisa, foram esclarecidos os objetivos e a metodologia proposta, apresentados os termos de consentimento por escrito e garantidos o acesso aos dados e 0 anonimato. As contribuições significativas das partici pantes ao longo do texto serão identificadas com uma letra seguida de um algarismo (U 1, U2, U3...). 


\section{Análiseediscussão dos resultados}

Os encontros foram realizados entre os meses de maio e julho de 2007, os quais foram gravados e, posteriormente, transcritos. Realizada a transcrição, seguiu-se com os procedimentos de análise dos dados das pesquisas qualitativas, utilizando a análise de conteúdo, ou seja, a extração das unidades conceituais de cada fala e os agrupamentos das categorias até al cançar as unidades temáticas que serão analisadas e discutidas em conformidade com a Carta dos Direitos dos U suários da Saúde.

Desde as primeiras reuniões, percebeu-se uma profunda e generalizada insatisfação com os serviços de saúde oferecidose, embora os participantes fossem oriundos de vários bairros e de cidades diferentes, as queixas e problemas apresentados eram muito similares. As categorias de análise que se destacaram nos provocaram como pesquisadoras e co-participantes a buscar e exigir ações concretas dos gestores, políticos e profissionais da saúde envolvidos com a atenção oferecida àquelas mulheres e suas famílias.

Nesses primeiros encontros, apresentaram-se três categorias de forma tão evidente e concreta que permitiram uma análise mesmo sem ter finalizado o estudo. São elas:

. O SU S associado à condição socioeconômica (o sistema dos pobres);

- Desinformação como característica do sistema e;

. Desqualificação e desinteresse dos profissionais de saúde.

A primeira categoria destaca o SUS associado à condição socioeconômica (o sistema dos pobres) e pode ser exemplificada com a seguinte expressão: "O SUS é para os pobres e por isso ninguém dá atenção" (U2 eU3) , afirmação deuma das mães que se fez acompanhar da concordância de todas as outras, manifestadas com expressões de angústia, raiva, sensação de impotência e de inferioridade.

Nesse momento, trouxemos para discussão o terceiro princípio da cartilha dos usuários, qual seja: todo cidadão tem direito ao atendimento humanizado, acolhedor elivre de qualquer discriminação. É direito dos cidadãos o atendimento acoIhedor na rede de serviços de saúde de forma humanizada, livre de qualquer discriminação, restrição ou negação em função de idade, raça, cor, etnia, orientação sexual, identidade de gênero, características genéticas, condições econômicas ou sociais, estado de saúde, ser portador de patologia ou pessoa vivendo com deficiência ${ }^{4}$. Tal princípio remete para o caráter universal do SU S como um sistema de saúde dirigido a todos os brasileiros, mas que ainda não se efetivou e se mostra, na prática, discriminatório e restrito.

Esse aspecto pode estar associado ao crescente desenvolvimento tecnocientífico que vem tornando a assi stência à saú de cada vez mais sofisticada e cara, o que acabou por instaurar, no campo da saúde, uma crescente impossibilidade deacesso aos recursos terapêuticos.

Toledo Filho ${ }^{8}$ destaca que, com o surgimento dos planos de saú de privados que passaram a comprar o serviço médico, as diferenças sociais ficaram ainda mais evidentes e excludentes. A segurança da qualidade da assistência passa, então, a ser comprada e assegurada para aqueles com poder aquisitivo um pouco melhor, ou seja, a saúde passa a obedecer à lógica do mercado, tornandose uma necessidade de consumo e não um direito, uma questão de vida.

Por mais que queiram transmutar a saúde em produtos consumíveis - sejam medicamentos e/ou tratamentos - ou em mercadorias a compor o imaginário das pessoas, transformando-a em símbolos de consumo, ela é, mesmo que virtualmente, mais do que isso, quer do ponto de vista individual, quer do ponto de vista coletivo. Saúde é mais do que "uma coisa"; ela é um valor e uma perspectiva: "ter saúde é o melhor remédio", segundo o dito popular. Saúdeé direito ${ }^{9}$.

Em outras palavras, permanece para um grande número de pessoas a garantia do sonho desfeito e a certeza de um relacionamento desinteressado, distantee muitas vezes antiético. Dequeadiantam, então, as altas e sofisticadas tecnologias, a complexidade dos procedimentos e as belíssimas estruturas físicas, se a garantia e a qualidade da assistência podem ser alcançadas apenas por uma pequena minoria da população?

O utro aspecto que merece destaque é o entendimento sobre as funções dos vários setores que compõem o SUS. Assim, verificamos que, quando as participantes criticavam o SUS, estavam se referindo às Unidades Básicas de Saúde nas quais eram atendidas, as quais, segundo elas, deveriam prestar assistência de saúde sempre que necessitassem, ou seja, sempre que se apresentem com "falta de saúde". Esqueciam-se, porém, que o hospital, onde seus fil hos estavam internados, também pertencia ao SUS, com oferta de serviço de qualidade e muito mais complexo e mais caro que aquele das unidades básicas.

Por que então pensar no SU S como o sistema dos pobres? 0 que é necessário fazer para mudar essa imagem? A atuação dos profissionais da saúde e gestores tem colaborado para afirmar esse imaginário? 0 que pode ser feito para ampliar a 
assistência etornar o SU S universal? Estas são questões que se destacam e suscitam novas reflexões.

A segunda categoria, desinformação como característica do sistema, ficou estabelecida a partir dessa afirmação: "Na verdade, hoje, nem tudo funciona na prática. Do que vocês estão discutindo, de muitas coisas os usuários têm o direito. [...] $\mathrm{N}$ a verdade, não épelo direito, maso SU S, eleestá defasado. [...] Por exemplo, aqui eu já vi diferenças no tratamento das pessoas, dos médicos, da atenção. Lá ninguém deu informação" (U4).

Essa foi também uma queixa que se tornou unânime entre as participantes. Consideraram um desrespeito 0 vaivém de informações e desinformações sobre onde ir, que papéis levar, para quem, quanto tempo de espera, o porquêda demora (geralmente superior a sessenta dias) para exames e consultas especializadas. É a prática do jogo do alheio: "isto não é comigo, é com ele", ou com o outro, em geral, 0 ausente. Nesse "jogo do empurra" de uma instituição para outra, queixa comum das usuárias durantes os encontros, se reproduz 0 jogo dos guichês da burocracia, que irresponsabiliza, um a um, os funcionários e se coloca como uma tática de ocultamento das próprias responsabilidades.

Destaca-se aqui o primeiro princípio da cartiIha, com o seguinte enunciado: todo cidadão tem direito ao acesso ordenado e organizado aos sistemas de saúde, isto é, acesso às ações e aos serviços de promoção, proteção e recuperação da saúde promovidos pelo Sistema Ú nico de Saúde. No detalhamento desse princípio, consta que, quando houver limitação circunstancial na capacidade de atendimento do serviço de saúde, fica sob responsabilidade do gestor local a pronta resolução das condições para 0 acolhimento e devido encaminhamento do usuário do SUS, devendo ser prestadas informações claras ao usuário sobre os critérios de priorização do acesso na localidade por ora indisponível. A prioridade deveser baseada em critérios de vulnerabilidadeclínica esocial, sem qualquer tipo de discriminação ou privilégio4.

A saúde, como direito, é garantida na constituição federal a partir de um dever do Estado e está colocado no texto da Lei Orgânica da Saúde no 8.080, de setembro de 1990 , que regulamenta o SUS. Uma segunda lei, a 8.142, de dezembro de 1990, dispõe sobrea participação da comunidade na gestão do SUS, instituindo duas instâncias colegiadas em cada esfera de governo (federal, estadual e municipal): as Conferências de Saúde e os ConseIhos de Saúde ${ }^{10,11}$.

Passados dezesseteanos, o quese percebeéuma participação popular pouco efetiva e muitas fragi- lidades nos mecanismos de controle social, tais como: a falta de legitimidade e irregularidades na composição dos consel hos; sua desarticulação com a sociedade; a falta de capacitação de gestores e conselheiros, ou seja, falta de informação quanto aos princípios e legislação do SUS relativos aos cidadãos de forma geral e pouca influência sobre a atuação das unidades básicas de saúde.

$\mathrm{Na}$ visão de Petry e Faria"12, "o controle social dos serviços de saúde representa um estágio el evado da sociedade organizada refletindo num real poder da população em interferir e modificar os rumos políticos, planos e programas de saúde".

Especificando o quarto princípio, apresenta-se o direito de poder participar dos processos de indicação e/ ou eleição de seus representantes nas conferências, nos consel hos nacional, estadual, do Distrito Federal, municipal e regional ou distrital de saúde e consel hos gestores de serviços".

Porém, ao questionarmos as participantes sobre o Conselho Local de Saúde ou o serviço de ouvidoria, mostraram desconhecer a existência de tais instâncias, o que evidencia o descompasso e grande distância entre a exigência sob forma de lei e de direito e o que se estabelece como prática efetiva do sistema de saúde. Não se percebem medidas sob o ponto de vista político em informar a população sobre a necessidade de partici pação nos espaços nos quais são tomadas decisões em saúde.

Outro aspecto que se destaca é a cultura da queixa e da reclamação, sem oferecer soluções ou buscar encontrá-las. A participação popular de forma efetiva nos consel hos locais de saúde talvez possa facilitar o entendimento e melhorar o sistema de informações institucional e interinstitucional, permitindo ao usuário sentir-se um sujeito de direitos e, mais ainda, ter seus direitos garantidos.

Esses aspectos estão previstos no sexto e último princípio com o seguinte enunciado: todo cidadão tem direito ao comprometimento dos gestores da saúde, das três esferas de governo, para que os princípios anteriores sejam cumpridos ${ }^{4}$.

Percebe-se, infelizmente, que as duas pontas do sistema se deslocam para lados contrários. De um lado os gestores, a classe política, que encontra dificuldades em encontrar estratégias eficazes de informar a população sobre seus direitos. Por outro lado, o desinteresse da população quanto a formas mais ativas de participação, pois, ao sentir-se um sujeito de direitos, esqueceseu dever como cogestor do sistema.

0 que é preciso/possível fazer para alterar essa cultura da qual estamos todos impregnados? 0 SU Sainda éviável?

A última categoria, desqualificação e desinte- 
resse dos profissionais de saúde, expressada dessa forma pelas participantes: “Eu sou usuário e quero que ele me trate bem, mas ele não trata bem"(U3). E também: "O usuário deveria seorientar mais, ir além. Se eu falar da palavra direito, eu tenho que saber o queéa palavra direito. Ter direito, uma pal avra muito linda. Mas que direito? Direito de quê?" (U1).

A falta de interesse ea carência de uma postura de escuta por parte dos profissionais nos remetem ao quarto princípio: todo cidadão tem direito a atendimento que respeite a sua pessoa, seus valores e seus direitos. 0 respeito à cidadania no Sistema de Saúde deve ainda observar, além de outros, os seguintes direitos: acesso aos mecanismos de escuta para apresentar sugestões, reclamações e denúncias aos gestores e às gerências das unidades prestadoras de serviços de saúde e às ouvidorias, sendo respeitada a privacidade, o sigilo e a confidencialidade4.

Também o segundo princípio da mesma carta pode ser citado como complemento: todo cidadão tem direito a tratamento adequado e efetivo para seu problema. É direito dos cidadãos terem atendimento resolutivo com qualidade, em função da natureza do agravo, com garantia de continuidade da aten ção, sempre que necessário. Além de atendimento com presteza, tecnologia apropriada e condições de trabal ho adequadas para os profissionais da saúde, acrescidos de informações sobre o seu estado de saúde, extensivas aos seus familiares e/ou acompanhantes, de maneira clara, objetiva, respeitosa, compreensível e adaptada à condição cultural, respeitados os limites éticos por parte da equipe de saúde4.

O desenvolvimento cada vez maior da ciênciae tecnologia tem muitos aspectos positivos, principalmente relacionados à melhoria da qualidade de vida e da saúde. As novas e constantes descobertas e tecnologias cada vez mais avançadas têm sido implementadas e adquiridas em busca da melhoria da assistência. Percebe-se, porém, que na prática nem sempre o aparato tecnológico é sinônimo demelhor assistência, uma vez que a sua utilização precisa não apenas de mãos habilidosas, mas que sejam também carinhosas e sensíveis. Parece quea tecnologia, em vez de aproximar, tem se colocado como uma barreira que afasta os seres humanos cuidadores daqueles que são cuidados.

Podemos observar, de modo geral, a necessidade de criar uma cultura de humanização que implica, prioritariamente, uma profunda valorização do potencial humano, passando pela equipe de saúde até al cançar os usuários, indivíduos e coletividade. A humanização não se concretiza se a atenção estiver centralizada unicamente no usuá- rio, mesmo que este seja a razão de ser das instituições de saúde. 0 cuidado humanizado, em síntese, será, também, reflexo das boas ou más relações de trabalho efruto do estímulo, da valorização e incentivo aos trabalhadores.

Para garantir o direito a atendimento com qualidade ehumanizado, se faz necessário investimento em qualificação dos profissionais. Eles formam uma terceira ponta no sistema de saúde, com aproximação ao sistema educacional, responsável pela formação de profissionais, e aos próprios gestores que devem permitir efavorecer a continuidadedessa formação através de investimentos em educação continuada.

Essas reflexões, pouco aprofundadas pela limitação de páginas e ainda longe de sua finalização, nos conduzem para o pensamento de que "não basta 0 avanço virtual da norma em considerar a saúde como direito. A cabeça, o modo de pensar, as representações, o imaginário dos trabal hadores de saúde - estes são os que dão forma a tais direitos à população ao atendê la no balcão, na consulta ou na portaria" 9 .

\section{Consideraçõesfinais}

Sob a égide da constituição de 1988, vivemos um novo momento democrático, com leis que, em princípio, defendem os direitos sociais e amparam a participação da população nas políticas de saúde.

Uma política, porém, não será implementada apenas pela vontade dos órgãos governamentais e/ou institucionais. Requer o comprometimento e envolvimento de todos, desde os usuários, profissionais e gestores, passando pelos políticos, cientistas, produtores de tecnologias e demais setores que formam o complexo sistema de saúde em nosso país.

A discussão sobre saúde e controle social necessita tomar distância da visão de saúde apenas como consumo, em que o controle selimita a verificar sea mercadoria condiz com seu rótulo. N essa perspectiva, a doença e as carências se tornam naturais, como coisas que devem acontecer, onde é "normal" ficar doente e consumir um "comprimido de saúde".

0 direito à saúde não se limita ao direito ao consumo de saúde, é mais que isso. Saúde é mais do que uma cesta de serviços, mesmo que públicos, embora sejam básicos à vida da população. "Isto supõe entendê-la não como um produto a ser consumido, mas, sobretudo, delinear o projeto que se quer como padrão de qualidade de vida de uma sociedadee, nela, de cada um dos cidadãos" 9 . 
Quanto mais o planejamento do SUS estiver articulado e integrado com a coletividade, tanto maior será a garantia de um serviço de saúde com qualidade e eqüidade. Não basta garantir 0 acesso ao sistema público. É preciso criar uma consciência política dos usuários para que não se tornem meros receptores das propostas governamentais. É preciso que todos os atores sociais estejam engajados e comprometidos na luta pela transformação da sociedade.

Esse estudo vem demonstrando que ainda há muito a ser feito no campo do controle social em saúde, em relação aos direitos dos usuários, sobre a participação popular em saúde.
Cabe aos profissionais que atuam nos serviços de saúde, formadores dos futuros profissionais, algumas vezes gestores e políticos e, muitas vezes, usuários desses mesmos serviços, não apenas refletir sobre essa temática, mas arregaçar as mangas e colocarem-se como instrumento de mudança. Deve-seir além de aceitar explicações quelevam apenas ao conformismo esentimento de incapacidade de mudar. Tal atitude ofusca e limita um mundo de possibilidades e medidas que visem estabelecer políticas eações de promoção, proteção e recuperação da saúde, motivando a participação popular nas decisões e na implementação de tais ações.
Colaboradores

DS Backes, M S Koerich, ACRL Rodrigues, LC Drago, P Klock eAL Erdmann participaram igualmente de todas as etapas da elaboração do artigo. 


\section{Referências}

1. Brasil. M inistério da Saúde. Gestão Financeira do SUS: M anual básico. 3a ed. Brasília: Ministério da Saúde; 2003.

2. Soares LTR. Ajuste neoliberal e o desajuste social na América Latina. Rio de Janeiro: UFRJ; 1999.

3. Brasil. Ministério da Saúde. Política Nacional de Humanização - HumanizaSU S [documento base]. Brasília: Ministério da Saúde; 2006a.

4. Brasil. M inistério da Saúde. Carta dos direitos dos usuários da saúde. Brasília: M inistério da Saúde; 2006b.

5. Thiollent M. M etodologia da pesquisa-ação. $2^{\underline{a}}$ ed. São Paulo: Cortez; 1986.

6. Thiollent M. Pesquisa-ação nas organizações. São PauIo: Atlas; 1997.

7. Franco MAS. Pedagogia da pesquisa-ação. Educação e Pesquisa 2005; 31(3):483-502.

8. Toledo Filho PG. Pensando a relação médico-paciente: uma proposta para humanização. $0 \mathrm{M}$ undo da Saúde 2003, 27(2):307-313.

9. 9. Sposati A, Lobo E. Social control over health policies. Cad Saúde Pública [periódico na Internet] 1992 [acessado 2007 Out 15]; 8(4):[cerca de 13 p]. Disponível em: http://www.scielo.br/scielo.php?script=sci_arttext \& pid=S0102-11X $1992000400003 \&$ Ing $=$ en\&nrm $=$ iso

10. Brasil. M inistério da Saúde. Lei Orgânica de Saúde. Brasília: Ministério da Saúde; 1990.

11. Brasil. M inistério da Saúde. Lei 8.142 , de 28 de dezembro de 1990. Dispõe sobre a participação da comunidade na gestão do Sistema Ú nico de Saúde SUS e sobre as transferências intergovernamentais de recursos financeiros na área da saúde e dá outras providências. [acessado 2007 ago 15]. Disponível em: http://conselho.saude.gov.br

12. Petry AP, Faria LC. O processo educativo em saúde como prática de Enfermagem junto aos Conselhos Locais de saúde para construção do controle social no SUS [trabalho de conclusão de curso]. Florianópolis (SC): Universidade Federal de Santa Catarina; 2004.

Artigo apresentado em 06/08/2007

Aprovado em 15/02/2008

Versão final apresentada em 31/03/2008 